\title{
Ab initio base fragment molecular orbital studies of influenza viral hemagglutinin HA1 full-domains in complex with sialoside receptors
}

\author{
Toshihiko Sawada ${ }^{\mathrm{a}, \mathrm{b}, *}$, Tomohiro Hashimoto ${ }^{\mathrm{c}}$, Hiroaki Tokiwa ${ }^{\mathrm{a}, \mathrm{d}}$, Tohru Suzuki ${ }^{\mathrm{e}}$, Hirofumi Nakano ${ }^{\mathrm{f}}$, \\ Hideharu Ishida ${ }^{\mathrm{g}}$, Makoto Kiso ${ }^{\mathrm{a}, \mathrm{g}}$,Yasuo Suzuki ${ }^{\mathrm{a}, \mathrm{b}, \mathrm{h}, *}$
}

${ }^{\mathrm{a} C}$ Core Research for Evolutional Science and Technology (CREST), Japan Science and Technology Agency (JST), Kawaguchi, Saitama 332-0012, Japan, ${ }^{\mathrm{b}}$ College of Life and Health Sciences, Chubu University, Kasugai, Aichi $487-$ 8501, Japan, 'Faculty of Regional Studies, Gifu University, 1-1 Yanagido, Gifu 501-1193, Japan, dDepartment of Chemistry, Faculty of Science, Rikkyo University, 3-34-1 Nishi-Ikebukuro, Tokyo 171-8501, Japan, 'The United Graduate School of Agricultural Science, Gifu University, Japan, ${ }^{\mathrm{f} D e p a r t m e n t}$ of Chemistry, Aichi University of Education, Kariya, Aichi 448-8542, Japan, ${ }^{g}$ Department of Applied Bioorganic Chemistry, Gifu University, Japan, hJapan and Global COE Program for Innovation in Human Health Sciences, University of Shizuoka School of Pharmaceutical Sciences, 52-1 Yada, Shizuoka 422-8526, Japan

*Correspondence to: Toshihiko Sawada, Email: sawada-t@aist.go.jp, Tel: +81 29 8613298, Fax: +81 29 8613171; Yasuo Suzuki, Email: suzukiy@isc.chubu.ac.jp, Tel/Fax: +81 568516391

Received 26 July 2008, Revised 28 October 2008, Accepted 30 October 2008, Published online 26 November 2008

J Mol Genet Med (2009), 3(1), 133-142

(C) Copyright The Authors: This is an open access article, published under the terms of the Creative Commons Attribution Non-Commercial License (http://creativecommons.org/licenses/by-nc/2.0/uk/). This license permits noncommercial use, distribution and reproduction of the article, provided the original work is appropriately acknowledged with correct citation details.

\begin{abstract}
Mutations in avian influenza A viral hemagglutinin HA1 domain may alter the binding specificity of HA for $\alpha$-sialosaccharide receptors, shifting the virus's host range from birds to humans. The amino acid mutations can occur at the sialoside binding site, as well as the antigenic site, far from the binding site. Thus, a theoretical study involving the in silico prediction of HA-sialosaccharide binding may require quantum chemical analysis of HA1 full domain complexed with sialosides, balancing a computational cost with model size of HA1-sialoside complex. In addition, there is no insight to relationship between the model size of HA1-sialoside complex and its binding energy. In this study, H3 subtype HA1 full domains complexed with avian- and human-type Neu5Aca(2-3 and 2-6)Gal receptor analogs was investigated by ab initio based fragment molecular orbital (FMO) method at the level of second-order Møller-Plesset perturbation (MP2)/6$31 \mathrm{G}$. Using this approach, we found avian H3 HA1 to bind to avian $\alpha 2-3$ receptor more strongly than to human $\alpha 2-6$ receptor in gas phase, by a value of $15.3-16.5 \mathrm{kcal} / \mathrm{mol}$. This binding benefit was larger than that in the small model complex. Analysis of the interfragment interaction energies (IFIEs) between Neu5Ac-Gal receptor and amino acid residues on the full domain of $\mathrm{H} 3 \mathrm{HA} 1$ also confirmed the higher avian $\mathrm{H} 3$-avian a2-3 binding specificity. It was particularly important to evaluate the IFIEs of amino acid residues in a $13 \AA$ radius around Neu5Ac-Gal to take account of long-range electrostatic interactions in the larger HA1sialoside complex model. These results suggest suitable size of HA1-sialoside complex is significant to estimate HA1-sialoside binding energy and IFIE analysis with FMO method.
\end{abstract}

KEYWORDS: Virus host range, sialosaccharide, lectin, ab initio, FMO, binding energy, interfragment interaction energy, second-order Møller-Plesset perturbation 


\section{INTRODUCTION}

Recent studies have revealed that binding specificities of influenza viral hemagglutinins(HA) with sialooligosaccharide receptors are involved in the virus host range determination (Suzuki, 2005; Matrosovich et al, 2006; Stevens et al, 2006a, Webster et al, 2006). Avian influenza viruses can bind to avian-type receptor Neu5Aca(2-3)Gal on human airway epithelium (Matrosovich et al, 2004) and lower respiratory tract (Shinya et al, 2006; van Riel et al, 2006). However, this infection mechanism does not cause pandemic human influenza. We must pay attention to the higher binding affinity of avian viruses to human-type receptor Neu5Aca(2-6)Gal (Shinya et al, 2005; Yamada et al, 2006; Chandrasekaran et al, 2008; Belser et al, 2008, Steavens et al, 2008). When the binding specificity of mutant influenza viral HA with human $\alpha 2-6$ ligand is predicted in advance, we can take measures against an outbreak of pandemic human influenza. However, a scientific framework for studies to predict changes in the host ranges of influenza viruses has not yet been established. We believe that, with high performance PC cluster, ab initio based fragment molecular orbital (FMO) studies of the HA-sialoside complexes will help to predict the chemical properties of HA-sialoside binding (Sawada et al, 2006, 2007, 2008; Iwata et al, 2008).

Influenza virion attaches to $\alpha$-sialoglycoproteins and $\alpha$ sialoglycolipids on the host cell surface via molecular interactions between the viral HA and sialooligosaccharide (Böttcher et al, 1999; Horimoto and Kawaoka, 2005). HA forms a trimer which has sialoside receptor binding sites on the surface of each HA1 domain (Skehel and Wiley, 2000). The binding site consists of 130-loop, 150-loop, 190-helix, and 220-loop, and their chemical behaviours allow avian viral HA to interact specifically with the avian Neu5Aca(23)Gal receptor (Ha et al, 2001, 2003; Gamblin et al, 2004; Stevens et al, 2004, 2006b; Russell et al, 2006). Amino acid substitutions at the sialoside binding site change HAsialoside binding properties (Lin and Cannon, 2002; Glaser et al, 2005; Yamada et al, 2006; Tumpey et al, 2007; Auewarakul et al, 2007; Yang et al, 2007). In addition, a substitution at HA1 antigenic site D, which is situated far from the sialoside binding site, also alters the relative binding specificity of HA with human/avian-type receptors (Suzuki et al, 1989). These results suggest that mutations on avian viral HA1 can shift the host range of virus from birds to humans, therefore, chemical prediction studies may require quantum chemical analyses of sialoside receptors in complex with the entire HA1 domain. At the same time, we should balance a computational cost with model size of HA1-sialoside complex. However, there is no insight into relationship between the model size of HA1-sialoside complex and its binding energy.

We previously reported the binding energies and interfragment stabilizations between avian $\mathrm{H} 3$ and disaccharide analogs of avian- and human-type Neu5Aca(2-3 and 2-6)Gal receptors (Sawada et al, 2008). In these study, we used small model complex of the binding site (70 amino acids) and conducted FMO calculations at the MP2/6-31G level to evaluate the intermolecular electrostatic interactions and dispersion interactions. However, this approach had to treat sensitively the peptide terminals in the very small binding site models. Recently, with a suitable PC cluster, FMO method was shown to calculate a viral HA-antibody complexes at the MP2 level (Mochizuki et al, 2008), as well as HA1 full domain-sialoside complexes.

In the FMO two-body terms method (FMO2), an HA1sialoside complex is divided into $N$ fragments, and molecular orbital calculations are carried out on each fragment $(I, J, . ., N)$ and fragment pairs $(I J, I K, I L, \ldots, J K$, $J L, \ldots,(N-1) N)$. Next, the total energy $E$ of the entire HA1sialoside complex is evaluated with the following equation:

$$
E=\sum_{\mathrm{I}}^{N} E_{\mathrm{I}}+\sum_{\mathrm{I}>J}^{N}\left(E_{\mathrm{IJ}}-E_{\mathrm{I}}-E_{\mathrm{J}}\right)
$$

where the terms represent summation of the fragment energies and interfragment interaction energies (IFIEs), respectively (Kitaura et al, 1999a,b).

Since the method estimates IFIEs by taking account of many-body corrections (Yamamoto et al, 2006; Yamagishi et al, 2006), we are able to analyze intermolecular stabilizations of Neu5Ac-Gal receptors with amino acid residues at the sialoside binding site on HA1.

In this study, we applied FMO method to influenza viral HA H3-subtype HA1 full domain complexed with the avian- and the human-type $\operatorname{Neu} 5 \operatorname{Ac} \alpha(2-3$ and 2-6)Gal disaccharides. Binding energies between HA1s and sialosides were computed at the FMO2-MP2/6-31G level. We analyzed relationships between HA1-siaoside binding energies and size-dependency of HA1-siaoside complexes. Besides interfragment stabilizations in the two kinds of larger HA1 complexes were compared to give some guidance for future large-scale FMO studies.

\section{MATERIALS AND METHODS}

\section{Computational analysis}

The H3-receptor complexes for the FMO studies were obtained from the energy minimum structures of avian and human A virus H3-subtype trimers in complex with Neu5Aca(2-3 or 2-6)Gal analogs as reported previously (Sawada et al, 2008). We clipped small model complex A, large-size complex $\mathbf{B}$, and full-size HA1 complex $\mathbf{C}$ from the geometry optimized avian/human H3 complexes (Figure 1). Peptide terminals in the models were treated as $\mathrm{NH}_{3}{ }^{+}$and $\mathrm{COO}^{-}$in a similar manner to that used in our previous studies. We computed the single point energies of the whole complexes $\left(E_{\text {complex }}\right)$, corresponding to H3 HA1 domains $\left(E_{\mathrm{H} 3}\right)$, and $\operatorname{Neu} 5 \mathrm{Ac} \alpha(2-3 / 6) \mathrm{Gal}\left(E_{\text {receptor }}\right)$ at the FMO2-MP2/6-31G level, followed by evaluation of H3sialoside binding energy $(\Delta \mathrm{E})$ by the following equation:

$$
\Delta E=\left(E_{\mathrm{H} 3}+E_{\text {receptor }}\right)-E_{\text {complex }}
$$

The HA1 domains were divided into single amino acid residue as a single fragment (with the exception of Cys S$\mathrm{S}$ Cys pairs) using automatic fragmentation scheme in 
ABINIT-MP package (http://www.ciss.iis.u-tokyo.ac.jp /fsis/en/index.html) (Figure 2). Neu5Ac-Gal receptors were treated as a single fragment charged to -1 (Figure 3 ). To compute neutral $\mathrm{H} 3$-sialoside system in gas phase, $\mathrm{H} 3$ HA1 domains in the complexes A-C were charged to +1 as same manner in our previous studies (Sawada et al, 2006, 2007,2008 ), namely several $\delta$-guanidium on $\operatorname{Arg}$ and $\varepsilon$ ammonium on Lys were de-protonated to be neutral form (Table 1). FMO calculations were carried out using ABINIT-MP program.

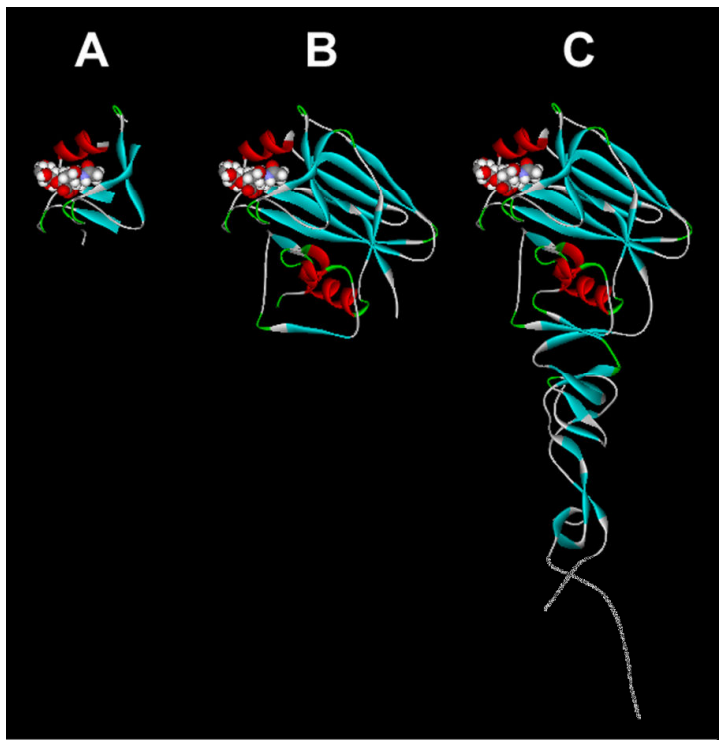

Figure 1. The complexes of influenza A virus H3 HA1 domain with Neu5Ac-Gal analog for the FMO-MP2/6-31G calculations A. The complex has the smallest receptor binding site (Sawada et al, 2006, 2008). The site has four peptides Asn96-Pro99, Gly129Tyr161, Gly181-Val196, and Asn216-Ile232 to be total 70 amino acids. B. Binding domain in the complex consists of $\operatorname{Arg}(\mathrm{Ile}) 62-$ Gly263 (202 amino acids, avian H3; Arg62, human H3; Ile62), C. The complex has the full size of HA1 domain (avian H3; Ser9-Lys326, human H3; Gln1-Thr328, Sawada et al, 2007). ribbon model; HA1, red; helix, blue; sheet, CPK model; Neu5Ac-Gal analog.

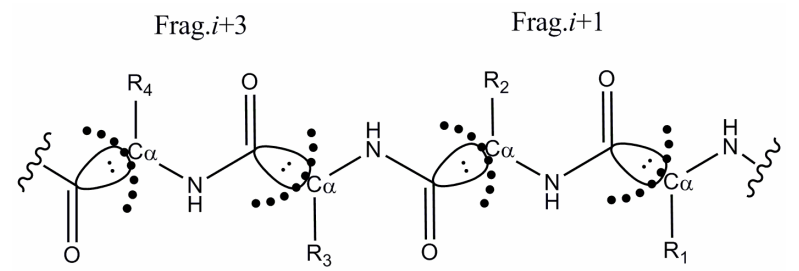

Frag. $i+4$

Frag. $i+2$

Frag. $i$

Figure 2. Schematic fragmentation of $\mathrm{H} 3 \mathrm{HA} 1$ domain. HA1 domain was fragmented by cutting $\mathrm{C} \alpha-\mathrm{C}$ bonds in accordance with general manner (Fedorov and Kitaura, 2006). C $\alpha$ were bond detached atoms. Fragment $1,2, \ldots, i, i+1, \ldots, N$ were treated as amino acid residue $1,2, \ldots, i, i+1, \ldots, N$.
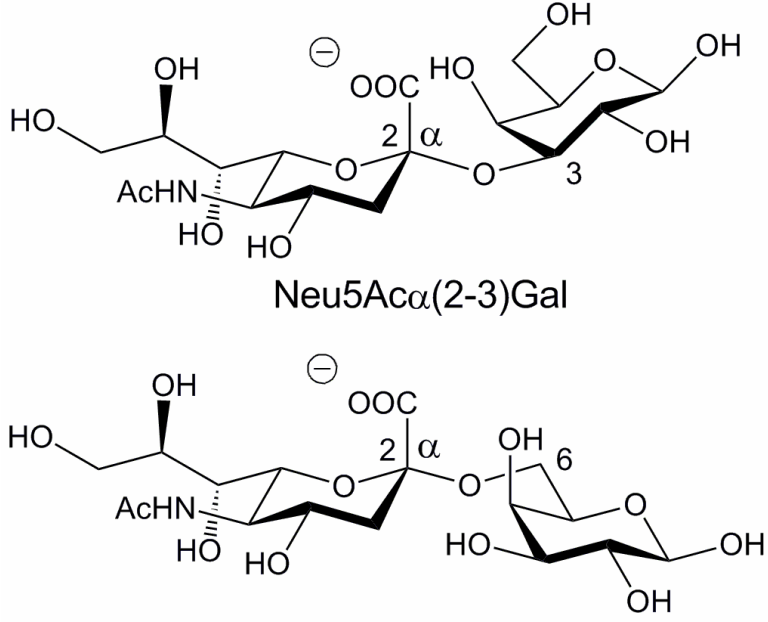

Neu5Ac $\alpha(2-6) G a l$

Figure 3. Schematic structures of avian and human receptor Neu5Ac $\alpha(2-3$ and 2-6)Gal

\section{RESULTS AND DISCUSSION}

Binding energies between HA1 and Neu5Aca(2-3 and 2-6)Gal receptors

Binding energies $(\Delta E \mathrm{~s})$ of the avian and human $\mathrm{H} 3$ complexes $\mathbf{B}, \mathbf{C}$ at the FMO-MP2/6-31G level are summarized in Tables 2 and 3. Avian $\mathrm{H} 3$ bound to avian receptor Neu5Aca(2-3)Gal stronger than to human receptor Neu5Ac $\alpha(2-6) \mathrm{Gal}$ by a value of 15.3-16.5 $\mathrm{kcal} / \mathrm{mol}$ (Table 2; entries 8, 9).

$\Delta E$ s of the larger avian $\mathrm{H} 3$ complexes $\mathbf{B}$ and $\mathbf{C}$ have 14.5$24.1 \mathrm{kcal} / \mathrm{mol}$ larger values than those of small complex $\mathbf{A}$ (Table 2; entries 2, 3, 5, 6) because the former two models take into account long-range electrostatic interactions between Neu5Ac-Gal and charged amino acid residues. With the long-range interaction, energy difference between $\Delta E_{\alpha 2-3}$ and $\Delta E_{\alpha 2-6}$ are 15.3 and $16.5 \mathrm{kcal} / \mathrm{mol}$ in the models $\mathbf{B}$ and $\mathbf{C}$ (Table 2; entries 8,9 ). These results suggest that model $\mathbf{B}$ has enough size for the binding energy calculation at the FMO-MP2 level. Consideration of more real HA trimer-sialoside system, trimerized model B may give an accurate binding energy with FMO method. Model $\mathbf{B}$ involves antigenic sites A, B, D, and E (Smith et al, 2004).

In the human H3-human $\alpha 2-6$ complex, full model $\mathbf{C}$ has a highest $\Delta E_{\alpha 2-6} 203.1 \mathrm{kcal} / \mathrm{mol}$, which is about 50 and 36 $\mathrm{kcal} / \mathrm{mol}$ larger than those of models $\mathbf{A}$ and $\mathbf{B}$ (Table 3; entries 1-3). In addition, energy difference in $\Delta E_{\alpha 2-6}$ between human H3 complex $\mathbf{A}$ and $\mathbf{B}$ (Table 3; entries 1, 2) is $15-16 \mathrm{kcal} / \mathrm{mol}$ larger than the corresponding differences in the avian $\mathrm{H} 3$ complexes (Table 2; entries 4, 5. Table 3; entries 4, 5). These data indicate that human $\mathrm{H} 3$ differs from avian $\mathrm{H} 3$ in terms of the relationship between $\Delta E_{\alpha 2-6}$ and model structure, whose details are discussed by IFIE analysis in next section. Here we note 
Table 1: Basic and acidic amino acid residues in the models A-C

\begin{tabular}{|c|c|c|c|c|c|c|c|c|}
\hline H3 & model & Arg & Lys & $\mathrm{His}^{*}$ & terminal $\mathrm{NH}_{3}{ }^{+}$ & Asp & Glu & $\begin{array}{l}\text { ternimal } \\
\mathrm{COO}^{-}\end{array}$ \\
\hline \multirow[t]{3}{*}{ Avian } & $\mathbf{A}^{* 1}$ & $\begin{array}{l}141^{* 3}, 150^{* 3}, \\
220,224^{* 3} \\
229^{* 3}\end{array}$ & 140,156 & 183(E), 184(E) & $\begin{array}{l}\text { Asn96, Gly129, } \\
\text { Gly181, Asn216 }\end{array}$ & & 158,190 & $\begin{array}{l}\text { Pro99, } \\
\text { Tyr161, } \\
\text { Val196, } \\
\text { Ile232 }\end{array}$ \\
\hline & B & $\begin{array}{l}62^{* 3}, 90, \\
109,141, \\
150,201, \\
207,208^{* 3}, \\
220,224, \\
229,255, \\
261\end{array}$ & $\begin{array}{l}140,156, \\
176,238, \\
259\end{array}$ & $\begin{array}{l}75(E), 183(E) \\
184(E)\end{array}$ & Arg62 & $\begin{array}{l}68,73,77, \\
85,101,104, \\
172,175, \\
241\end{array}$ & $\begin{array}{l}82,89, \\
119,123, \\
158,190\end{array}$ & Gly263 \\
\hline & $\mathbf{C}$ & $\begin{array}{l}57,62^{* 3}, 90, \\
109,141, \\
150,201, \\
207,208^{* 3}, \\
220,224, \\
229,255, \\
261,269^{* 3}, \\
321\end{array}$ & $\begin{array}{l}27,50, \\
140,156, \\
176,238, \\
259,264, \\
292,299, \\
307,310, \\
315,326^{* 3}\end{array}$ & $\begin{array}{l}\text { 17(E), 18(E), } \\
56(\mathrm{E}), 75(\mathrm{E}), \\
\text { 183(E), 184(E) }\end{array}$ & Ser9 & $\begin{array}{l}31,32,60, \\
68,73,77, \\
85,191,104, \\
172,175, \\
241,271, \\
275,291\end{array}$ & $\begin{array}{l}35,41,82, \\
89,119, \\
123,158, \\
190,280, \\
325\end{array}$ & Lys326 \\
\hline \multirow[t]{3}{*}{ Human } & $\mathbf{A}^{* 1}$ & $\begin{array}{l}141^{* 3}, 150 \\
220^{* 3}, 224^{* 3} \\
229^{* 3}\end{array}$ & $140,156^{* 3}$ & 183(E), 184(E) & $\begin{array}{l}\text { Asn96, Gly129, } \\
\text { Gly181, Asn216 }\end{array}$ & & 190 & $\begin{array}{l}\text { Pro99, } \\
\text { Tyr161, } \\
\text { Val196, } \\
\text { Ile232 }\end{array}$ \\
\hline & $\mathbf{B}^{* 2}$ & $\begin{array}{l}90,109,141, \\
150,201, \\
207,208, \\
220,224, \\
229,255, \\
261^{* 3}\end{array}$ & $\begin{array}{l}92^{* 3}, 140 \\
156,176 \\
238,259^{* 3}\end{array}$ & $\begin{array}{l}75(\mathrm{P}), 183(\mathrm{E}) \\
184(\mathrm{E})\end{array}$ & Ile62 & $\begin{array}{l}63,68,73, \\
77,85,101, \\
104,172, \\
175,241\end{array}$ & $\begin{array}{l}82,89, \\
119,123, \\
190\end{array}$ & Gly263 \\
\hline & $\mathbf{C}^{* 2}$ & $\begin{array}{l}57,90,109, \\
141,150, \\
201,207, \\
208,220, \\
224,229 \\
255,261^{* 3} \\
269^{* 3}, 321^{* 3}\end{array}$ & $\begin{array}{l}27,50,92, \\
140,156, \\
176,238, \\
259,264, \\
292,299, \\
307,310, \\
315,326\end{array}$ & $\begin{array}{l}\text { 17(D), 18(E), } \\
56(\mathrm{E}), 75(\mathrm{P}), \\
\text { 183(E), 184(E) }\end{array}$ & Gln1 & $\begin{array}{l}2,7,31,32, \\
60,63,68, \\
73,77,85, \\
101,104, \\
172,175, \\
241,271, \\
275,291\end{array}$ & $\begin{array}{l}35,41,82, \\
89,119, \\
123,190 \\
280,325\end{array}$ & Thr328 \\
\hline
\end{tabular}

${ }^{*_{1}}$ Sawada et al, 2006, 2008

${ }^{*}$ Sawada et al, 2007

${ }^{*}$ Side chain $\delta$-guanidium on Arg and $\varepsilon$-ammonium on Lys are neutralized in order to compute neutral H3-sialoside complex.

${ }^{* 4}$ There are three types of histidine. E; neutral form with NE proton. D; neutral form with ND proton. P; positive charged form with ND and NE protons.

that monotonous increase of $\Delta E_{\alpha 2-6}$ in the human $\mathrm{H} 3$ larger (Table 3; entries 2, 3, 5, 6). Their details are complex is probably a pretense (Table 3; entries 1-3) discussed by IFIE analysis in next section.

because the $\Delta E_{\alpha 2-6}$ does not simply increase at the FMO-

$\mathrm{RHF} / \mathrm{STO}-3 \mathrm{G}$ level as the model complex became larger (Sawada et al, 2007).

Gln226Leu substitution on avian $\mathrm{H} 3$ changes the binding specificity from avian $\alpha 2-3$ to human $\alpha 2-6$ (Rogers et al, 1985). In the smallest model $\mathbf{A}, \Delta E_{\alpha 2-6}$ of avian Gln226Leu H3 complex is quite similar to that of human H3 complex (Table 3; entries 1, 4. Sawada et al, 2008). However, the similarity is lost as the model size becomes

In this section, we have analyzed a relationship between HA1-siaoside binding energy in gas phase and sizedependency of HA1-siaoside complex with charged amino acid residues. Avian H3 HA1 binds to avian $\alpha 2-3$ receptor $15.3-16.5 \mathrm{kcal} / \mathrm{mol}$ more strongly than to human $\alpha 2-6$ receptor in gas phase, and this binding benefit is larger than corresponding in small model complex. Avian H3 HA1 differs from human $\mathrm{H} 3$ in terms of the relationship between $\Delta E_{\alpha 2-6}$ and model structure. To obtain more 
Table 2. Binding energies in $\mathrm{kcal} / \mathrm{mol}$ of avian $\mathrm{H} 3$ with avian/human Neu5Aca(2-3/6)Gal receptors

\begin{tabular}{clcc}
\hline Entry & & Model & MP2/6-31G \\
\hline 1 & $\Delta E_{\alpha 2-3}$ & A & $180.4^{* 1}$ \\
2 & & B & 204.5 \\
3 & & C & 200.0 \\
& & & \\
4 & $\Delta E_{\alpha 2-6}$ & A & $169.0^{* 1}$ \\
5 & & B & 189.2 \\
6 & & C & 183.5 \\
& & & \\
7 & $\Delta E_{\alpha 2-3}-\Delta E_{\alpha 2-6}$ & A & $11.4^{* 1}$ \\
8 & & B & 15.3 \\
9 & & C & 16.5 \\
\hline
\end{tabular}

${ }^{*_{1}}$ These data were previously reported in Sawada et al (2008).

Table 3. Binding energies in $\mathrm{kcal} / \mathrm{mol}$ of human and avian Gln226Leu H3s with human Neu5Ac $\alpha(2-6)$ Gal receptors

\begin{tabular}{cccc}
\hline Entry & H3 & Model & $\begin{array}{c}\Delta \boldsymbol{E}_{\mathbf{a 2}-\mathbf{6}} \\
\text { MP2/6-31G }\end{array}$ \\
\hline 1 & Human & A & $154.3^{* 1}$ \\
2 & & B & 190.2 \\
3 & & C & 203.1 \\
& & & \\
4 & Avian & & $157.6^{* 1}$ \\
5 & & A & 177.4 \\
6 & & C & 172.3 \\
\hline
\end{tabular}

${ }^{* 1}$ These data were previously reported in Sawada et al (2008).

accurate total energies and binding energies of HA1sialoside complexes, we will apply the following approaches in the near future: [a] Fragmentation of HA1 domain into larger blocks, e.g., two amino acid residues as a fragment (Nemoto et al, 2005; Fukuzawa et al, 2006; Nakanishi et al, 2007), [b] Applying larger basis sets, such as $6-31(+) \mathrm{G}(\mathrm{d})$, where diffuse function was added on the negative charged groups $\mathrm{COO}^{-}$, [c] Correlation of basis set superposition error, [d] QM/MM or multilayer FMO (Fedorov et al, 2005) geometry optimization of HA1sialoside complex with explicit water solvent after structural equilibrations are carried out by molecular dynamics simulations, [e] Utilizing more approvable expressions to calculate the binding energy of protein with ligand (Nemoto et al, 2005; Nakanishi et al, 2007), [f] Major part of larger binding energy in gas phase should be correlated by de-solvation enegy (Nakanishi et al, 2007).

Mainly, binding free energy of HA to sialoside in aqueous phase governs HA-sialoside binding affinity (Chong et al, 1999; Pathiaseril and Woods, 2000; Leach, 2001). To evaluate the binding free energy, many elements in the thermodynamic cycle of binding free energy are calculated by using various approximations and computational methods (Nakanishi et al, 2007). FMO-MP2 calculations can provide enthalpic energies of the HA-sialoside complex, isolated HA, and sialoside receptor as some elements in the thermodynamic cycle. However, for in silico predictions of the avian HA mutant-human $\alpha 2-6$ binding, we require a simple and qualitative framework.

In order to establish the appropriate framework, we propose a trial such that in silico simulations are utilized to estimate various kinds of differences ( $\Delta$ values) between the original avian HA-human $\alpha 2-6$ binding (control) and HA mutant-human $\alpha 2-6$ bindings, where $\Delta$ values are e.g., relative binding energies of HA mutants to $\alpha 2-6$ ligand, relative interfragment stabilizations, and relative flexibilities of HA mutant-human $\alpha 2-6$ complexes. Since recent experimental studies have revealed binding properties of original avian HA and its mutants to human Q2-6 receptor, in silico simulation of the reported avian HA-human $\alpha 2-6$ systems will afford a reliable relationship between $\Delta$ values and mutation positions on HA1 domain. This approach avoids computing the binding free energy. Instead, we need to adopt chemical intuition to select suitable $\Delta$ values. The $\Delta$ values should satisfy some requirements, such as approximate independence each other, relation to the binding free energy, and needless large-sized sampling. In the future, we will develop the concept, and attempt to find the $\Delta$ values using MD simulation, QM/MM calculation, and FMO-MP2 studies.

Analysis of interfragment interaction energies between Neu5Aca(2-3 and 2-6)Gal and amino acids on HA1

In the above section, we have mentioned that human $\mathrm{H} 3$ differs from avian $\mathrm{H} 3$ in terms of the relationship between $\Delta E_{\alpha 2-6}$ and model structure (Table 2; entries 4, 5, Table 3; entries 1,2$)$, besides there is no similarity of $\Delta E_{\alpha 2-6}$ between human Leu226 H3 complex and avian Gln226Leu H3 complex in the model B (Table 3). These results are explained by analysis of IFIEs between Neu5Aca(2-6)Gal and amino acid residues on $\mathrm{H} 3$ in the models $\mathbf{A}$ and $\mathbf{B}$ (Table 4). Charged amino acid residues strongly interacts with negative charged Neu5Aca(26) Gal, and whose interaction energies affect the human $\alpha 2-6-\mathrm{H} 3$ binding energy. Since expanding model size from complex $\mathbf{A}$ to $\mathbf{B}$ with neutral HA-sialoside system demands us to de-protonate and re-protonate amino acid side chain $\delta$-guanidium on Arg and $\varepsilon$-ammonium on Lys, modification of model $\mathbf{A}$ range in the human $\mathrm{H} 3$ model $\mathbf{B}$ quite differs from that of avian $\mathrm{H} 3$ complex (Table 1; lines Arg and Lys). Thus, in terms of the relationship between $\Delta E_{\alpha 2-6}$ and model structure, human $\mathrm{H} 3$ has a different tendency from the corresponding avian $\mathrm{H} 3$ (Table 4; entries 9, 12). Avian Gln226Leu H3 has the same tendency as avian $\mathrm{Gln} 226 \mathrm{H} 3$ that causes the nonsimilarity of $\Delta E_{\alpha 2-6}$ between avian Gln226 $\mathrm{H} 3$ and human Leu226 H3. Comparing amino acid sequence of avian H3 with human $\mathrm{H} 3$ shows four substitutions at $62,63,92$, and 102 on the model $\mathbf{B}$ range excluding the range of model $\mathbf{A}$ (Figure 4), then the charged residues affect $\mathrm{H} 3$-sialoside binding energies (Table 4; entry 14). Expanding model size from $\mathbf{B}$ to $\mathbf{C}$ decreases the $\Delta E_{\alpha 2-6}$ by $\sim 5.1-5.7 \mathrm{kcal} / \mathrm{mol}$ 
Table 4. The sums of IFIEs between human Neu5Ac $\alpha(2-6)$ Gal with amino acid residues on avian and human $\mathrm{H} 3$ in the models A and B at the FMO-MP2/6-31G level

\begin{tabular}{|c|c|c|c|c|}
\hline \multirow[b]{2}{*}{ Entry } & & \multirow[b]{2}{*}{ amino acid residues } & \multicolumn{2}{|c|}{ sum of IFIEs (kcal/mol) } \\
\hline & & & avian $\mathrm{H} 3$ & human $\mathrm{H} 3$ \\
\hline 1 & model A & substituted residues (non-charge) ${ }^{* 1}$ & 70.6 & 72.3 \\
\hline 2 & & substituted residues (charge) ${ }^{* 2}$ & -16.7 & 1.2 \\
\hline 3 & & Arg, Lys, His(P), Asp, Glü ${ }^{* 3}$ & 71.2 & 40.2 \\
\hline 4 & & terminal residues ${ }^{* 4}$ & 2.6 & 0.3 \\
\hline 5 & & others & 108.1 & 105.9 \\
\hline 6 & & total & 235.8 & 219.9 \\
\hline & model $\mathbf{B}$ & model $\mathbf{A}$ range in model $\mathbf{B}$ & & \\
\hline 7 & & substituted residues (non-charge) ${ }^{* 1}$ & $69.2(-1.4)^{* 10}$ & $70.3(-2.0)^{* 10}$ \\
\hline 8 & & substituted residues (charge) ${ }^{* 2}$ & $-16.8(-0.1)$ & $1.2(0.0)$ \\
\hline 9 & & Arg, Lys, His(P), Asp, Glu ${ }^{* 5}$ & $156.8(85.6)$ & 158.3(118.1) \\
\hline 10 & & terminal residues ${ }^{* 6}$ & $6.3(3.7)$ & $4.4(4.1)$ \\
\hline 11 & & others & $79.3(-28.8)$ & $73.7(-32.2)$ \\
\hline \multirow[t]{2}{*}{12} & & total & $294.8(59.0)$ & $307.9(88.0)$ \\
\hline & & model $\mathbf{B}$ range excluding model $\mathbf{A}$ & & \\
\hline 13 & & substituted residues (non-charge) ${ }^{* 7}$ & -0.2 & -0.3 \\
\hline 14 & & substituted residues (charge) ${ }^{* 8}$ & 0.4 & -14.6 \\
\hline 15 & & Arg, Lys, His(P), Asp, Glu ${ }^{* 5}$ & -67.4 & -62.5 \\
\hline 16 & & terminal residues $^{* 9}$ & 4.2 & 4.1 \\
\hline 17 & & others & 3.8 & 1.5 \\
\hline 18 & & total & -59.2 & -71.8 \\
\hline 19 & & model $\mathbf{B}$ total (entry $12+18$ ) & 235.6 & 236.1 \\
\hline
\end{tabular}

${ }^{*}{ }_{1}$ amino acid positions are 137, 144, 145, 160, 182, 193, 226, 227, and 228

${ }^{*}$ amino acid position is 158

${ }^{* 3}$ their form are shown in table 1; model $\mathbf{A}$

${ }^{* 4} \mathrm{~N}$ - and C-terminal residues are charged +1 and -1 , respectively (table 1; model $\mathbf{A}$ )

${ }^{*}$ their form are shown in table 1 ; model $\mathbf{B}$

${ }^{* 6}$ the residues do not charged because they are parts of peptide chain in model $\mathbf{B}$.

${ }^{* 7}$ amino acid position is 102

*8 amino acid positions are 63 and 92

${ }^{* 9} \mathrm{~N}$ - and C-terminal residues are 62 and 263 as shown in table 1; model $\mathbf{B}$

${ }^{* 10}$ values in parenthesis are given by [model $\left.\mathbf{A}\right]$-[model $\mathbf{A}$ range in model $\left.\mathbf{B}\right]$

in the avian $\mathrm{H} 3$ complexes (Tables 2, 3; entries 5, 6), but 5; entries 1 and 2, 5 and 6 , Table 6; entries 11 and 12, 15 increases $13.1 \mathrm{kcal} / \mathrm{mol}$ in human $\mathrm{H} 3$ complex (Table 3; and 16), $24 \mathrm{kcal} / \mathrm{mol}$ larger in the human $\mathrm{H} 3$ complex entries 2, 3). These results are mainly caused by (Table 5; entries 1 and 2,5 and 6 ). Thus, model $\mathbf{A}$ is too interfragment long-range electrostatic interactions of small to evaluate the intermolecular stabilization. In our Neu5Ac-Gal with charged amino acid residues.

Changing the aspects of IFIEs analysis gives some guidance how much range $(\AA)$ around Neu5Ac-Gal analog in the gas phase HA1 complex is significant to evaluate sialsoside-HA1 interaction. The sums of interfragment interaction energies (s-IFIEs) between Neu5Aca(2-3 and 2-6) Gal and amino acid residues in the models $\mathbf{B}$ and $\mathbf{C}$ at the FMO-MP2/6-31G level are summarized in Tables 5 and 6. s-IFIEs of amino acid residues within a $13 \AA$ radius around Neu5Ac-Gal were 41 to $43 \mathrm{kcal} / \mathrm{mol}$ larger than the s-IFIEs in model $\mathbf{A}$ range in the avian $\mathrm{H} 3$ complex (Table study, Neu5Ac-Gal analogs are charged -1 , which strongly interacts with amino acids residues in $13 \AA$ radius around Neu5Ac-Gal by interfragment long-range electrostatic interactions. As some common factors in the partial model $\mathbf{B}$ and full model $\mathbf{C}$, s-IFIEs within $13 \AA$ radius around Neu5Ac-Gal give similar values 358.4 and $357.3 \mathrm{kcal} / \mathrm{mol}$ in the avian H3-avian $\alpha 2-3$ complex (Table 5 ; entries 2,6), 331.2 and $332.0 \mathrm{kcal} / \mathrm{mol}$ in the human H3-human 2-6 complex (Table 6; entries 2, 6), 324.8 and $323.7 \mathrm{kcal} / \mathrm{mol}$ in the avian Gln226Leu H3-human $\alpha 2-6$ complex (Table 6; entries 12,16). Besides, the addition of IFIEs in charged amino acids to the s-IFIEs of the $13 \AA$ 
Table 5. Sum of IFIEs between avian/human Neu5Aca(2-3 and 2-6)Gal and amino acid residues on avian $\mathrm{H} 3$ models B and C at the FMO-MP2/6-31G level

\begin{tabular}{|c|c|c|c|c|c|}
\hline \multirow[b]{2}{*}{ H3 } & \multirow[b]{2}{*}{ model } & \multirow[b]{2}{*}{ amino acid residues } & \multicolumn{2}{|c|}{ Sum of IFIEs in kcal/mol } & \multirow[b]{2}{*}{$\Delta^{* 1}$} \\
\hline & & & avian $\alpha 2-3$ & human $\alpha 2-6$ & \\
\hline 1 Avian & B & $\operatorname{model} \mathbf{A}^{* 2}$ & 317.5 & 294.8 & 22.7 \\
\hline 2 & & $13 \AA^{* 3}$ & 358.4 & 337.2 & 21.2 \\
\hline 3 & & $13 \AA+$ charged residues ${ }^{* 4}$ & 260.4 & 237.0 & 23.4 \\
\hline 4 & & all (Arg62-Gly263) & 258.6 & 235.6 & 23.0 \\
\hline 5 & $\mathbf{C}$ & $\operatorname{model} \mathbf{A}^{* 2}$ & 316.4 & 293.7 & 22.7 \\
\hline 6 & & $13 \AA^{* 3}$ & 357.3 & 336.1 & 21.2 \\
\hline 7 & & $13 \AA+$ charged residues ${ }^{* 4}$ & 251.9 & 227.8 & 24.1 \\
\hline 8 & & model B (Arg62-Gly263) & 253.7 & 230.7 & 23.0 \\
\hline 9 & & all (Ser9-Lys326) & 252.5 & 228.7 & 23.8 \\
\hline
\end{tabular}

${ }^{*_{1}} \Delta$ represents [sum of IFIEs between avian $\alpha 2-3$ and amino acids]-[sum of IFIEs between human $\alpha 2-6$ and amino acids].

${ }^{* 2}$ model A consists of 70 amino acid residues (Asn96-Pro99, Gly129-Tyr161, Gly181-Val196, Asn216-Ile232, Figure 5)

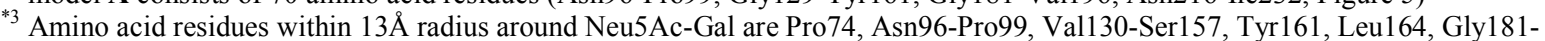
Gln197, Asn216-Pro221, Val223-Ile232, Asn250-Ala253, and Arg255.

${ }^{*}$ Charged residues are listed in table 1

Table 6. Sum of IFIEs between human Neu5Aca(2-6)Gal and amino acid residues on human Leu226 and avian Gln226Leu H3 models $\mathbf{B}$ and $\mathbf{C}$ at the FMO-MP2/6-31G level

\begin{tabular}{cllr}
\hline Entry $\mathbf{H 3}$ & Model & amino acid residues & human $\boldsymbol{\alpha 2 - 6}$ \\
\hline $\mathbf{1}$ Human & $\mathbf{B}$ & model A & 307.9 \\
$\mathbf{2}$ & & $13 \AA$ & 331.2 \\
$\mathbf{3}$ & & $13 \AA+$ charged residues & 238.9 \\
$\mathbf{4}$ & & all(Ile62-Gly263) & 236.1 \\
& & & \\
$\mathbf{5}$ & $\mathbf{C}$ & model A & 308.5 \\
$\mathbf{6}$ & & $13 \AA$ & 332.0 \\
$\mathbf{7}$ & & $13 \AA+$ charged residues & 248.2 \\
$\mathbf{8}$ & & model B (Ile62-Gly263) & 254.8 \\
$\mathbf{9}$ & & Ser9-Lys326 & 255.0 \\
$\mathbf{1 0}$ & & all(Gln1-Thr328) & 248.1 \\
$\mathbf{1 1}$ Aian Gln226Leu & $\mathbf{B}$ & model A & 282.4 \\
$\mathbf{1 2}$ & & $13 \AA$ & 324.8 \\
$\mathbf{1 3}$ & & $13 \AA+$ charged residues & 224.2 \\
$\mathbf{1 4}$ & & all(Arg62-Gly263) & 222.4 \\
$\mathbf{1 5}$ & & & 216.1 \\
$\mathbf{1 6}$ & & model A & 323.7 \\
$\mathbf{1 7}$ & & $13 \AA$ & 215.6 \\
$\mathbf{1 9}$ & & arg62-Gly263 & 2.5 \\
\hline
\end{tabular}




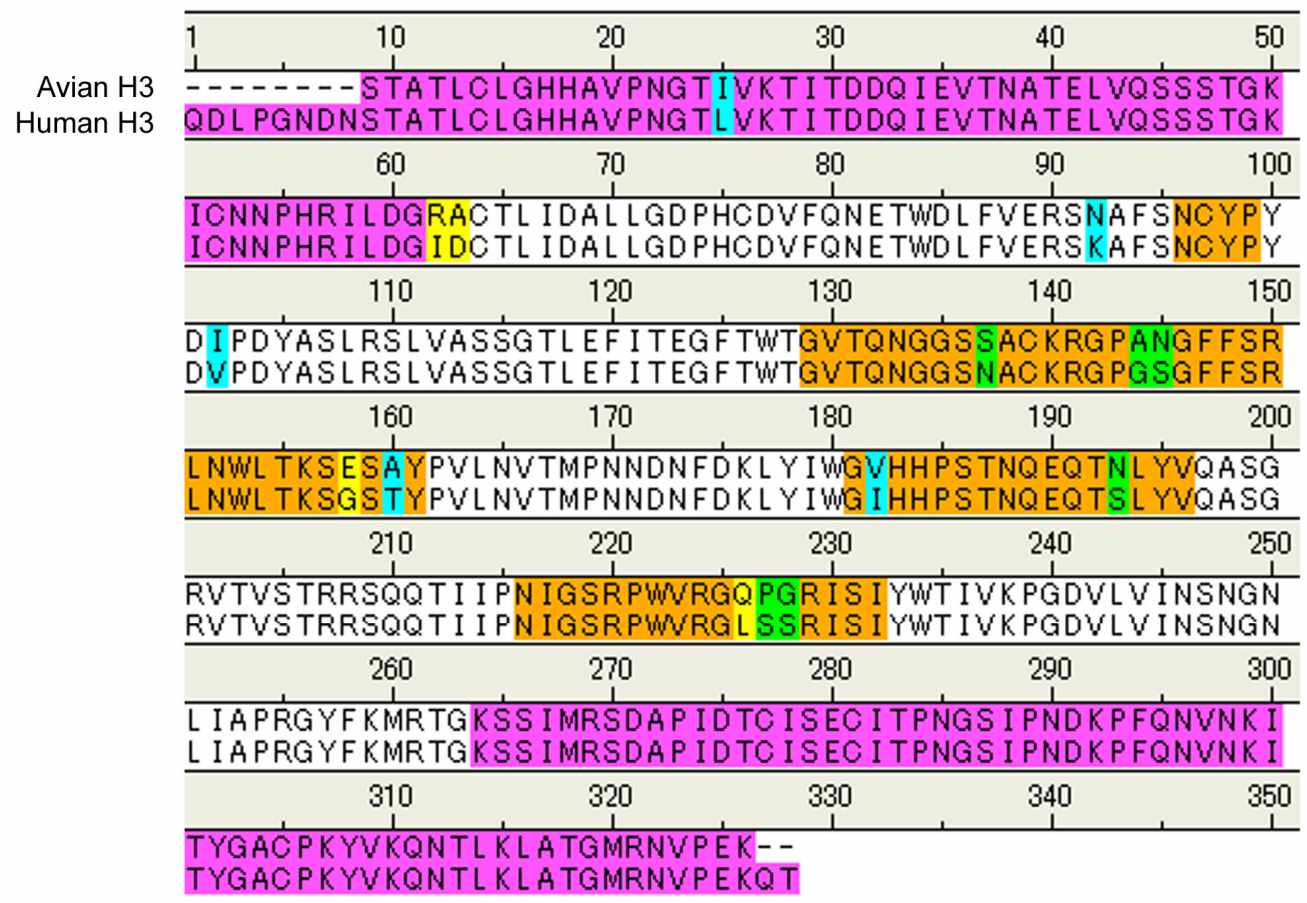

Figure 4. Sequence alignments of avian and human H3 HA1 in the model complexes $\mathbf{A}, \mathbf{B}$, and $\mathbf{C}$ : Yellow; non-matching residue, green; weak matching residues, light blue; strong matching residue, brown; smallest binding site in the model $\mathbf{A}$, purple; difference in the model $\mathbf{B}$ and $\mathbf{C}$.

radius residues affords similar values to the corresponding s-IFIEs of all amino acids (Table 5; entries 3 and 4, 7 and 9, Table 6; entries 3 and 4, 7 and 10, 13 and 14, 17 and 19). In the full model $\mathbf{C}$, the s-IFIEs of all amino acid residues are almost same with that of model $\mathbf{B}$ range (Table 5; entries 8, 9. Table 6; entries 8 and 9, 18 and 19). These results suggest that adequate IFIE analysis requires the amino acids in a $13 \AA$ radius around Neu5Ac-Gal in model B. In the human $\mathrm{H} 3$ model $\mathbf{C}$, negative charged Asp2 and 7 un-stablize the complex to give slightly lower s-IFIEs $248.1 \mathrm{kcal} / \mathrm{mol}$ than s-IFIEs of Ser9-Lys326 (Table 6; entries 9, 10).

Our IFIE analysis in the larger models $\mathbf{B}$ and $\mathbf{C}$ at the FMO-MP2/6-31G level confirms that avian $\mathrm{H} 3$ interacts with avian $\alpha 2-3$ receptor at 21 to $24 \mathrm{kcal} / \mathrm{mol}$ more strongly than with the human $\alpha 2-6$ receptor (Table 5 ; line $\Delta)$. In the previous study, s-IFIEs of thirteen amino acid residues in the avian H3-avian $\alpha 2-3$ complex $\mathbf{A}$ is about 10 $\mathrm{kcal} / \mathrm{mol}$ larger than that of avian $\mathrm{H} 3$-human $\alpha 2-6$ complex with a sensitive treatment of various charged residues (Sawada et al. 2008). Thus we should evaluate the s-IFIEs in the larger models B or C. Comparing human H3-human 22-6 with avian Gln226Leu H3-human $\alpha 2-6$, the former has $25.5-27.3 \mathrm{kcal} / \mathrm{mol}$ larger s-IFIEs of the model $\mathbf{A}$ range (Table 6; entries 1 and 11, 5 and 15). The energy difference decreases in comparison with corresponding of the $13 \AA$ radius range (Table 6; entries 2 and 12, 6 and 16).

\section{CONCLUSIONS}

Influenza viral H3 HA1 domains in complex with Neu5Aca(2-3 and 2-6)Gal analogs were studied at the FMO-MP2/6-31G level. Avian H3 bound to the avian-type receptor Neu5Aca(2-3)Gal 15.3 to $16.5 \mathrm{kcal} / \mathrm{mol}$ more strongly than to the human-type receptor Neu5Aca(26)Gal. Sialoside binding domain Arg(Ile)62-Gly263 (202 amino acids, avian H3; Arg62, human H3; Ile62) was enough size for estimating the binding energy of HA1 monomer-Neu5Ac-Gal disaccharide complex. We analyzed IFIEs between the Neu5Ac $\alpha(2-3 / 6) \mathrm{Gal}$ and amino acid residues on $\mathrm{H} 3 \mathrm{HA} 1$ to find that it is important to evaluate the IFIEs of amino acid residues within $13 \AA$ radius around Neu5Ac-Gal coupled with more accurate evaluation of long-range electrostatic interactions. These results demonstrated the relationships between the model sizes of HA1-sialoside complexes, their binding energies and sum of the IFIEs, then gave some guidance toward in silico prediction studies about HA-sialosides binding properties.

\section{ACKNOWLEDGEMENTS}

This work was supported by CREST, Japan Science and Technology Agency (JST), and a Grant-in-Aid (No. 17101007 to M. Kiso.) for Scientific Research from Japan Society for the Promotion of Science. 


\section{COMPETING INTERESTS}

None declared.

\section{LIST OF ABBREVIATIONS}

HA: Hemagglutinin

Neu5Ac: $\alpha$-N-acetyl-D-neuraminic acid

Gal: $\beta$-D-galactose

FMO: Fragment molecular orbital

MP2: Second-order Møller-Plesset perturbation

IFIE: Interfragment interaction energy

s-IFIEs: Sum of interfragment interaction energies

\section{REFERENCES}

Auewarakul P, Suptawiwat O, Kongchanagul A et al. 2007. An avian influenza $\mathrm{H} 5 \mathrm{~N} 1$ virus that binds to a human-type receptor. J Virol, 81, 9950-9955.

Belser JA, Blixt O, Chen L-M et al. 2008. Contemporary North American influenza $\mathrm{H} 7$ viruses possess human receptor specificity: implications for virus transmissibility. Proc Natl Acad Sci USA, 105, 7558-7563.

Böttcher C, Ludwig K, Herrmann A, van Heel M, and Stark H. 1999. Structure of infuenza haemagglutinin at neutral and at fusogenic $\mathrm{pH}$ by electron cryo-microscopy. FEBS lett, 463, 255-259.

Chandrasekaran A, Srinivasan A, Raman R et al. 2008. Glycan topology determines human adaptation of avian $\mathrm{H} 5 \mathrm{~N} 1$ virus hemagglutinin. Nat Biotechnol, 26, 107-113.

Chong LT, Duan Y, Wang L, Massova I, and Kollman PA. 1999. Molecular dynamics and free-energy calculations applied to affinity maturation in antibody 48G7. Proc Natl Acad Sci USA, 96, 14330-14335.

Fedorov DG, Ishida T, Kitaura K. 2005. Multilayer formulation of the fragment molecular orbital method (FMO). J Phys Chem A, 109, 2638-2646.

Fedorov, DG and Kitaura, K. 2006. Theoretical development of the fragment molecular orbital (FMO) method. In Modern methods for theoretical physical chemistry of biopolymers, eds. Starikov, EB, Lewis, JP and Tanaka, S. p3-38. Amsterdam: Elsevier.

Fukuzawa K, Mochizuki Y, Tanaka S, Kitaura K and Nakano T. 2006. Molecular interactions between estrogen receptor and its ligand studied by the ab initio fragment molecular orbital method. J Phys Chem B, 110, 16102-16110.

Gamblin SJ, Haire LF, Russell RJ et al. 2004. The structure and receptor binding properties of the 1918 influenza hemagglutinin. Science, 303, 1838-1842.

Glaser L, Stevens J, Zamarin D, Wilson IA, García-Sastre A, Tumpey TM, Basler CF, Taubenberger JK and Palese P. 2005. A single amino acid substitution in 1918 influenza virus Hemagglutinin Changes Receptor Binding Specificity. J Virol, 79, 11533-11536.

Ha Y, Stevens DJ, Skehel JJ and Wiley DC. 2001. X-ray structures of $\mathrm{H} 5$ avian and $\mathrm{H} 9$ swine influenza virus hemagglutinins bound to avian and human receptor analogs. Proc Natl Acad Sci USA, 98, 11181-11186.

Ha Y, Stevens DJ, Skehel JJ and Wiley DC. 2003. X-ray structure of the hemagglutinin of a potential $\mathrm{H} 3$ avian progenitor of the 1968 Hong Kong pandemic influenza virus. Virology, 309, 209-218.

Horimoto T and Kawaoka Y. 2005. Influenza: lessons from past pandemics, warnings from current incidents. Nat Rev Microbiol, 3, 591-600.

Iwata T, Fukuzawa K, Nakajima K et al. 2008. Theoretical analysis of binding specificity of influenza viral hemagglutinin to avian and human receptors based on the fragment molecular orbital method. Comput Biol Chem, 32, 198-211.

Kitaura K, Sawai T, Asada T, Nakano T and Uebayasi M. 1999a. Pair interaction molecular orbital method: an approximate computational method for molecular interactions. Chem Phys Lett, 312, 319-324.

Kitaura K, Ikeo E, Asada T, Nakano T and Uebayasi M. 1999b. Fragment molecular orbital method: an approximate computational method for large molecules. Chem Phys Lett, 313, 701-706.

Leach AR. 2001. Molecular modeling: principles and applications, Pearson education Limited, Essex, UK, 2nd ed.

Lin AH and Cannon PM. 2002. Use of pseudotyped retroviral vectors to analyze the receptor-binding pocket of hemagglutinin from a pathogenic avian influenza A virus ( $\mathrm{H} 7$ subtype). Virus Res, 83, 43-56.

Matrosovich MN, Matrosovich TY, Gray T et al. 2004. Human and avian influenza viruses target different cell types in cultures of human airway epithelium. Proc Natl Acad Sci USA, 101, 4620-4624.

Matrosovich MN, Klenk H-D and Kawaoka Y. 2006, Receptor specificity, host-range, and pathogenicity of influenza viruses. In: Kawaoka Y (Ed) Influenza virology current topics, Caister Academic Press, Wymondham, UK, pp95-137.

Mochizuki Y, Yamashita K, Murase Tet al. 2008. Large scale FMO-MP2 calculations on a massively parallel-vector computer. Chem Phys Lett, 457, 396-403.

Nakanishi I, Fedorov DG and Kitaura K. 2007. Molecular recognition mechanism of FK506 binding protein: an allelectron fragment molecular orbital study. Protein Struct Func Bioinfo, 68, 145-158.

Nemoto T, Fedorov DG, Uebayasi $M$ et al. 2005. Ab initio fragment molecular orbital (FMO) method applied to analysis of the ligand-protein interaction in a pheromone-binding protein. Comput Biol Chem, 29, 434-439.

Pathiaseril A and Woods RJ. 2000. Relative energies of binding for antibody carbohydrate-antigen complexes computed from free energy simulations. J Am Chem Soc, 122, 331-338.

Rogers GN, Daniels RS, Skehel JJ et al. 1985. Host-mediated selection of influenza virus receptor variants. sialic acid$\alpha 2,6 \mathrm{Gal}$-specific clones of $\mathrm{A} / \mathrm{duck} / \mathrm{Ukraine} / 1 / 63$ revert to sialic acid- $\alpha 2,3 \mathrm{Gal}$-specific wild type in ovo. J Biol Chem, 260, $7362-7367$.

Russell RJ, Stevens DJ, Haire LF, Gamblin SJ and Skehel JJ. 2006. Avian and human receptor binding by hemagglutinins of influenza A viruses. Glycoconjugate J, 23, 85-92.

Sawada T, Hashimoto T, Nakano H et al. 2006. Why does avian influenza $A$ virus hemagglutinin bind to avian receptor stronger than to human receptor? ab initio fragment molecular orbital studies. Biochem Biophys Res Commun, 351, 40-43.

Sawada T, Hashimoto T, Nakano H et al. 2007. Influenza viral hemagglutinin complicated shape is advantageous to its binding affinity for sialosaccharide receptor. Biochem Biophys Res Commun, 355, 6-9.

Sawada T, Hashimoto T, Tokiwa $\mathrm{H}$ et al. 2008. Ab initio fragment molecular orbital studies of influenza virus hemagglutinin-sialosaccharide complexes toward chemical clarification about the virus host range determination. Glycoconjugate J, DOI 10.1007/s10719-008-9141-9.

Shinya K, Hatta M, Yamada S et al. 2005. Characterization of a human H5N1 influenza A virus isolated in 2003. J Virol, 79, 9926-9932.

Shinya K, Ebina M, Yamada S et al. 2006. Avian flu: influenza virus receptors in the human airway. Nature, 440, 435-436.

Skehel JJ and Wiley DC. 2000. Receptor binding and membrane fusion in virus entry: the influenza hemagglutinin. Ann Rev Biochem, 69, 531-569.

Smith DJ, Lapedes AS, de Jong JC et al. 2004. Mapping the antigenic and genetic evolution of influenza virus. Science, $305,371-376$. 
Stevens J, Corper AL, Basler CF et al. 2004. Structure of the uncleaved human H1 hemagglutinin from the extinct 1918 influenza virus. Science, 303, 1866-1870.

Stevens J, Blixt O, Paulson JC and Wilson IA. 2006a. Glycan microarray technologies: tools to survey host specificity of influenza viruses. Nat Rev Microbiol, 857-864.

Stevens J, Blixt O, Tumpey TM et al. 2006b. Structure and receptor specificity of the hemagglutinin from an $\mathrm{H} 5 \mathrm{~N} 1$ influenza virus. Science, 312, 404-410.

Stevens J, Blixt O, Chen L-M et al. 2008. Recent avian H5N1 viruses exhibit increased propensity for acquiring human receptor specificity. J. Mol. Biol. 381, 1382-1394.

Suzuki Y, Kato H, Naeve CW and Webster RG. 1989. Singleamino-acid substitution in an antigenic site of influenza virus hemagglutinin can alter the specificity of binding to cell membrane-associated gangliosides. J Virol, 63, 42984302.

Suzuki Y. 2005. Sialobiology of influenza: molecular mechanism of host range variation of influenza viruses. Biol Pharm Bull, 28, 399-408.
Tumpey TM, Maines TR, Hoeven NV et al. 2007. A Two Amino Acid Change in the Hemagglutinin of the 1918 Influenza Virus Abolishes Transmission. Science, 315, 655-659.

van Riel D, Munster VJ, de Wit E et al. 2006. H5N1 virus attachment to lower respiratory tract. Science, 312, 399.

Webster RG, Peiris M, Chen H and Guan Y. 2006. H5N1 outbreaks and enzootic influenza. Emerg Infect Dis, 12, 3-8.

Yang Z-Y, Wei C-J, Kong W-P et al. 2007. Immunization by avian $\mathrm{H} 5$ influenza hemagglutinin mutants with altered receptor binding specificity. Science, 317, 825-828.

Yamada S, Suzuki Y, Suzuki T et al. 2006. Haemagglutinin mutations responsible for the binding of $\mathrm{H} 5 \mathrm{~N} 1$ influenza $\mathrm{A}$ viruses to human-type receptors. Nature, 444, 378-382.

Yamagishi K, Yamamoto K, Yamada S and Tokiwa H. 2006. Functions of key residues in the ligand-binding pocket of vitamin D receptor: fragment molecular orbital-interfragment interaction energy analysis. Chem Phys Lett, 420, 465-468.

Yamamoto K, Abe D, Yoshimoto N et al. 2006. Vitamin D receptor: ligand recognition and allosteric network. J Med Chem, 49, 1313-1324. 